\title{
RENÉ N6: THIRD GENERATION SINGLE CRYSTAL SUPERALLOY
}

\author{
W.S. Walston, K.S. O'Hara, E.W. Ross, T.M. Pollock ${ }^{*}$ and W.H. Murphy
}

GE Aircraft Engines, Cincinnati, $\mathrm{OH} 45215$

* Carnegie Mellon University, Pittsburgh, PA 15213

\begin{abstract}
A new third generation single crystal superalloy has been developed for aircraft engine turbine airfoil applications. This alloy, René N6, is microstructurally stable and is approximately $30^{\circ} \mathrm{C}$ stronger than the second generation single crystal, René N5. A new type of instability phenomena, SRZ, was encountered in the alloy development process. SRZ is a cellular precipitation reaction that primarily occurs beneath coatings, but can also be found along grain boundaries. René N6 was developed to avoid the detrimental SRZ, while maintaining excellent creep strength. The mechanical properties and environmental resistance of René N6 are covered and compared to similar superalloys René N6 has undergone extensive engine testing and currently is being utilized for production engines.
\end{abstract}

\section{Introduction}

Since their development in the late 1980 's, second generation, single crystal superalloys have attained success in both commercial and military aircraft engines. These alloys typically contain 3 wt.\% Rhenium, which distinguishes them from first generation single crystal superalloys. The achievement of microstructural stability in these alloys involved control of topologically close packed (TCP) phases that could precipitate in moderate amounts after long times at temperatures above $900^{\circ} \mathrm{C},{ }^{[1,2]}$ but were not detrimental to properties.

Development of third generation single crystal alloys proceeded with increases in refractory element content. The development of an early, experimental composition, alloy $5 \mathrm{~A},{ }^{[3]}$ showed that there were new stability issues associated with the additions of higher levels of refractory elements. Not only was the amount of TCP increased over prior alloys, but a ncw microstructural instability was discovered. [4] This detrimental instability occurred under coatings, along grain boundaries and within the microstructure. The instability under coatings was termed secondary reaction zone (SRZ) because it occurred beneath the primary diffusion zone between the coating and the alloy. A structurally similar instability occurred along grain boundaries and in

$$
\text { Superalloys } 1996
$$

Edited by R. D. Kissinger, D. J. Deye, D. L. Anton

A. D. Cetel, M. V. Nathal, T. M. Pollock, and D. A. Woodford

The Minerals, Metals \& Materials Society, 1996 dendrite cores. These features were called cellular colonies. The SRZ and cellular colonies consisted of a three-phase constituent with a $\gamma^{\prime}$ matrix containing $\gamma$ and P phase (TCP) needles. The $\gamma$ and P phase needles tended to be aligned perpendicular to the growth interface. The cellular colonies in the dendrite core were responsible for decreases in creep rupture life of over $50 \%$ in some cases.

The discovery of SRZ raised new issues in the further development of third generation single crystal superalloys. It was found that Re was the element most responsible for the formation of SRZ. Thus, the levels of Re and other refractory elements had to be carefully balanced to yield good microstructural stability and creep rupture strength. SRZ under coatings also caused coating compatibility to be a central focus of the alloy development effort. The goal in developing René N6 was to design an alloy that achicved a $30^{\circ} \mathrm{C}$ improvement in creep rupture strength over the second generation single crystal alloy, René N5, possessed both good environmental resistance and microstructural stability and did not form SRZ.

\section{Alloy Development Approach}

The development of René N6 was based upon work on alloy $5 \mathrm{~A}$ and similar experimental alloys. Figure 1 shows a schematic of the alloy development practice. Initial single crystal castings of each alloy were produced at GE Aircraft Engines. Some alloy series were conducted using a "design of experiments" approach to evaluate individual and interactive elemental effects. Heat treatment trials were conducted on selected alloys to determine the proper solution heat treatment temperature for dissolution of the $\gamma / \gamma^{\prime}$ eutectic. Microstructural stability evaluations consisted of measuring the amount of TCP in $1093^{\circ} \mathrm{C}$ furnace exposures and in failed creep rupture specimens. Evaluations for SRZ consisted of evaluating different coatings and surface preparation techniques to determine an alloy's propensity to form SRZ. The susceptibility to formation of cellular colonies in dendrite cores was evaluated by using as-cast specimens to accentuate the amount of dendritic segregation. 
Creep rupture specimens were tested at 982 and $1093^{\circ} \mathrm{C}$ in the uncoated and coated conditions. Environmental testing consisted of an $1177^{\circ} \mathrm{C}$ Mach 1 oxidation test, a $927^{\circ} \mathrm{C} / 5 \mathrm{ppm}$ salt hot corrosion test and a $816^{\circ} \mathrm{C} / 899^{\circ} \mathrm{C} / 2 \mathrm{ppm}$ salt cyclic hot corrosion test. A limited number of alloys were evaluated further using $135 \mathrm{~kg}$ master heats. These alloys were evaluated using a wider range of test conditions, stability exposures and coating conditions. At this point, the castability and manufacturability evaluations were initiated.

Final alloy selection was based on the mechanical properties, TCP and SRZ stability evaluations, environmental resistance and castability of the candidate alloys. Following alloy selection, casting and manufacturing programs continued along with the initiation of efforts to obtain design data. Design data included a comprehensive compilation and analysis of physical and mechanical properties using uncoated and coated specimens. A wide variety of engine tests were conducted to assess the behavior of the alloy in various configurations. Finally, the production release of the alloy culminated the alloy development process.

\section{René N6 Composition}

The compositions of several second and third generation single crystal alloys are shown in Table I. The second generation alloys contain 3 wt.\% Re, while the third generation alloys have significantly higher levels of Re. The Re content of René N6 was most important in determining the balance between creep rupture strength and microstructural stability with respect to both TCP phase formation and SRZ occurrence. Relatively high levels of $\mathrm{Co}$ and low levels of $\mathrm{Cr}$ were also selected to benefit stability. High levels of Ta were found to be beneficial to high temperature strength and castability. ${ }^{[5]}$ While the elements Hf, C and B were initially not utilized in single crystal supcralloys, it has been found by GE Aircraft Engines that they are beneficial to improving the tolerance for casting defects, such as low angle grain boundaries, ${ }^{[6]}$ and for other properties, such as castability and environmental resistance. Yttrium was intentionally added to improve the adherence of the protective aluminum oxide layer formed in service. ${ }^{[7,8]}$

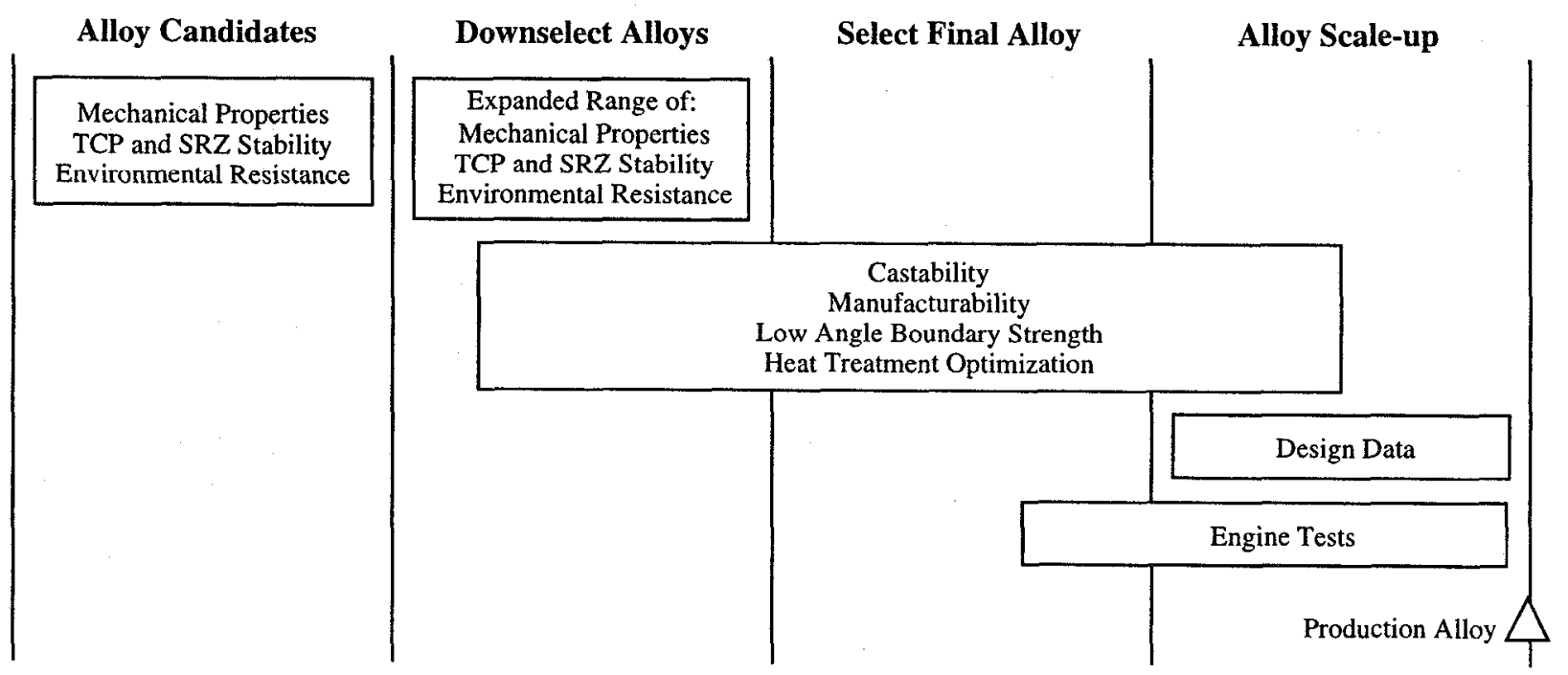

Figure 1. Alloy development approach for René N6.

Table I. Compositions of Second and Third Generation Single Crystal Superalloys (wt.\%)

\begin{tabular}{|c|c|c|c|c|c|c|c|c|c|c|c|c|c|c|c|}
\hline Alloy & $\mathrm{Co}$ & $\mathrm{Cr}$ & $\mathrm{Mo}$ & $\mathrm{W}$ & $\mathrm{Re}$ & $\mathrm{Ta}$ & $\mathrm{Al}$ & $\mathrm{Ti}$ & $\mathrm{Nb}$ & $\mathrm{Hf}$ & $\mathrm{C}$ & $\mathrm{B}$ & $\mathrm{Y}$ & $\mathrm{P}$ & Ref. \\
\hline \hline & \multicolumn{10}{|c|}{ Second Generation Single Crystals } \\
\hline René N5 & 7.50 & 7.00 & 1.50 & 5.00 & 3.00 & 6.50 & 6.20 & 0.00 & 0.00 & 0.15 & 0.05 & 0.004 & 0.01 & 8.63 & {$[9]$} \\
\hline CMSX-4 & 9.00 & 6.50 & 0.60 & 6.00 & 3.00 & 6.50 & 5.60 & 1.00 & 0.00 & 0.10 & 0.00 & 0.00 & 0.00 & 8.70 & {$[10]$} \\
\hline PWA 1484 & 10.00 & 5.00 & 2.00 & 6.00 & 3.00 & 8.70 & 5.60 & 0.00 & 0.00 & 0.10 & 0.00 & 0.00 & 0.00 & 8.95 & {$[11]$} \\
\hline SC180 & 10.00 & 5.30 & 1.70 & 5.00 & 3.00 & 8.50 & 5.20 & 1.00 & 0.00 & 0.10 & 0.00 & 0.00 & 0.00 & 8.84 & {$[12]$} \\
\hline & & \multicolumn{10}{|c|}{ Third Generation Single Crystals } & & & \\
\hline CMSX-10K & 3.30 & 2.30 & 0.40 & 5.50 & 6.30 & 8.40 & 5.70 & 0.30 & 0.10 & 0.03 & 0.00 & 0.00 & 0.00 & 9.10 & {$[13]$} \\
\hline CMSX-10Ri & 7.00 & 2.65 & 0.60 & 6.40 & 5.50 & 7.50 & 5.80 & 0.80 & 0.40 & 0.06 & 0.00 & 0.00 & 0.00 & 9.05 & {$[13]$} \\
\hline Alluy 5A & 12.50 & 4.50 & 0.00 & 5.75 & 6.25 & 7.00 & 6.25 & 0.00 & 0.00 & 0.15 & 0.05 & 0.004 & 0.01 & 8.91 & {$[3]$} \\
\hline René N6 & 12.50 & 4.20 & 1.40 & 6.00 & 5.40 & 7.20 & 5.75 & 0.00 & 0.00 & 0.15 & 0.05 & 0.004 & 0.01 & 8.97 & {$[14]$} \\
\hline
\end{tabular}




\section{Microstructure and Heat Treatment}

The solution heat treatment cycle for René N6 was carefully developed to provide acceptable levels of $\gamma / \gamma$ eutectic and incipient melting. Heat treatment trials to determine the levels of solutioning and incipient melting were conducted, resulting in over a $20^{\circ} \mathrm{C}$ window for acceptable solution heat treatment, as shown in Figure 2. It is well known that Re strongly segregates to the dendrites during solidification, and this can promote cellular colony formation. ${ }^{[4]}$ It was found that longer solution heat treatment times can reduce the level of $\mathrm{Re}$ segregation and prevent cellular colony formation in the dendrite cores. [15] Based on this work, CMSX-10 also employs an extended solution heat treatment cycle in an attempt to improve stability. ${ }^{[16]}$ The effect of the longer solution heat treatment cycles on the amount of TCP phase precipitation in René N6 was also studied. It was found that solution heat treatment time at maximum temperature had no effect on TCP formation.

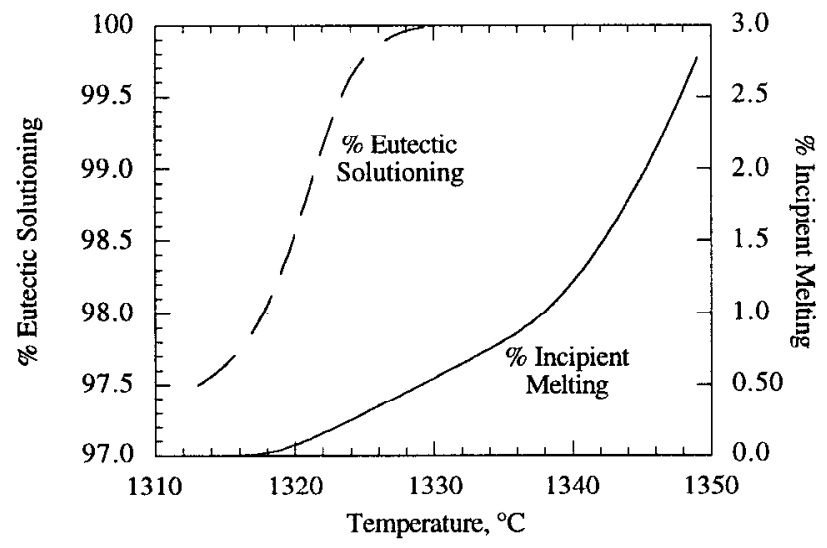

Figure 2. Effect of solution heat treat temperature on the amount of solutioning and incipient melting.

Creep rupture properties were also evaluated as a function of solution heat treatment time at $1320^{\circ} \mathrm{C}$. Figure 3 shows that the rupture lives for as-cast specimens were about $60 \%$ of the life of solution heat treated specimens. Further, there were no detrimental effects of longer solution heat treatment times on rupture life. In fact, there was a slight increase in rupture life at both 982 and $1093^{\circ} \mathrm{C}$. The need for longer heat treatment times must be balanced with the cost of performing the heat treatment. For René N6, the longer solution heat treatment served as insurance against the formation of the cellular colonies in the dendrite cores. Thus, extremely long times were not needed, as may be the case for less stable alloys. The optimum solution heat treatment cycle for René N6 was determined to be $1315-1335^{\circ} \mathrm{C}$ for approximately six hours. The effect of cooling rate from the solution temperature was evaluated, with the selected cooling rate yielding an initial $\gamma^{\prime}$ cube edge length of approximately $0.45 \mu \mathrm{m}$.

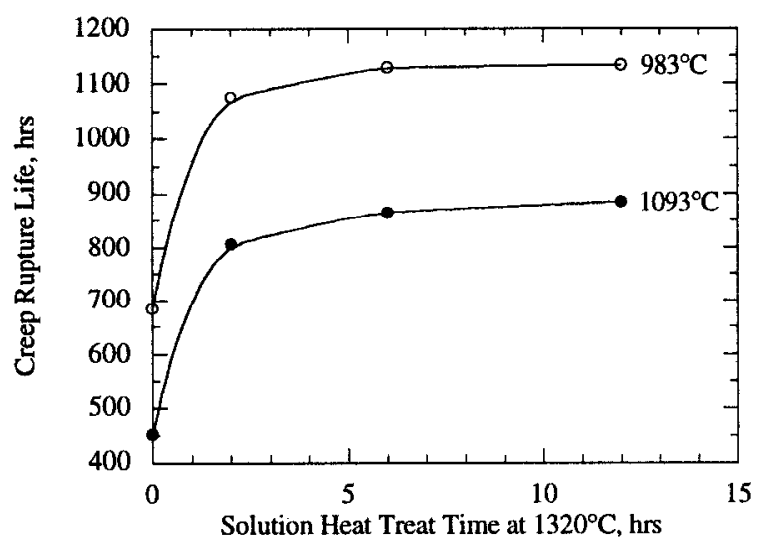

Figure 3. Rupture lives as a function of solution heat treatment time.

The effect of different primary age and simulated coating cycle temperatures was evaluated on alloy $5 \mathrm{~A}$ to determine the effect on creep rupture properties within this class of alloys. Figure 4 shows that there was little change in the rupture life at $871^{\circ} \mathrm{C}$ as a function of the primary age temperature. This high tolerance to varying heat treatments is an advantage in developing manufacturing cycle parameters for turbine airfoils of René N6. The fully heat treated microstructure of René N6 consists of approximately 65 vol.\% of cuboidal $\gamma$ precipitates in a $\gamma$ matrix.

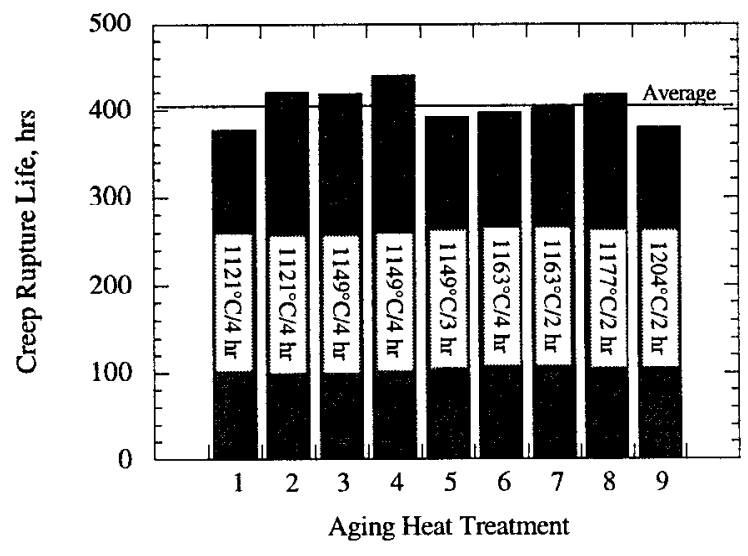

Figure 4. Effect of primary age heat treatment cycle on rupture life.

\section{Microstructural Stability}

The microstructural stability at temperatures above $1000^{\circ} \mathrm{C}$ was a key concern in the development of René N6. TCP phase formation is typically observed in many single crystal superalloys, especially those containing Re, although a small amount of TCP is not considered detrimental to creep rupture and other properties. Figure 5 shows the amount of TCP formed at $1093^{\circ} \mathrm{C}$ after 500 hours compared to CMSX10Ri. The small amount of TCP phases that precipitated at elevated temperatures in René N6 did not detrimentally affect creep rupture properties, even at lives of $1000 \mathrm{hrs}$. 


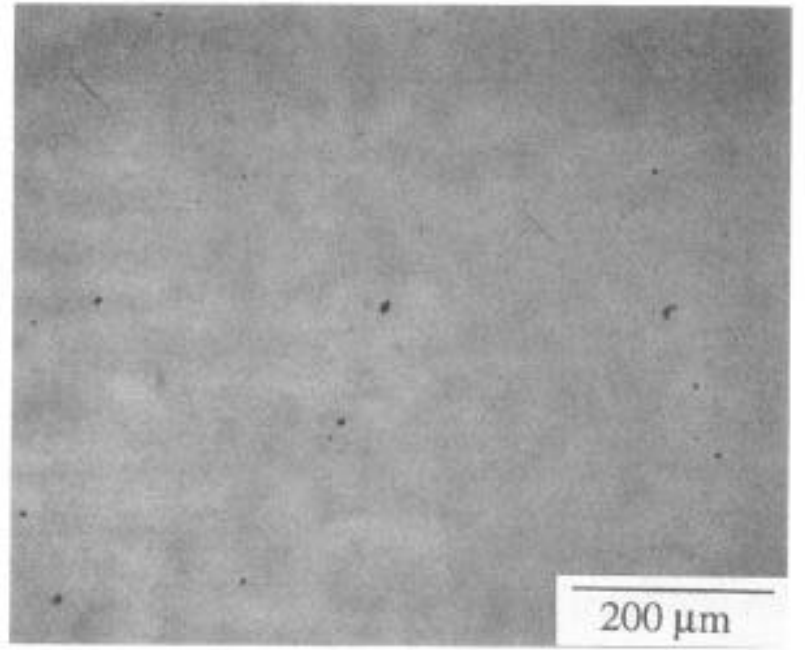

(a)

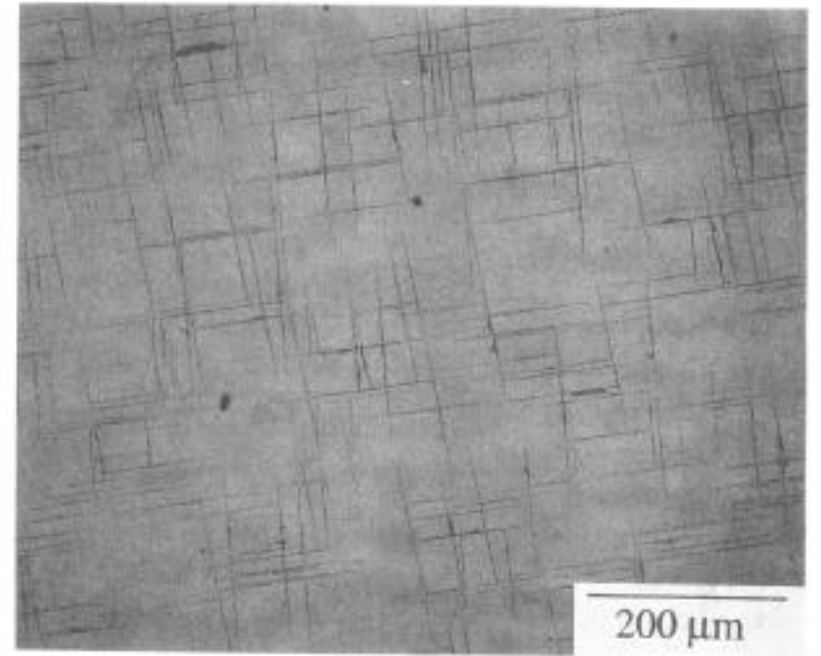

(b)

Figure 5. Amount of TCP phase precipitation after $500 \mathrm{hr}$ at $1093^{\circ} \mathrm{C}$ in (a) Rene N6 and (b) CMSX-10Ri.

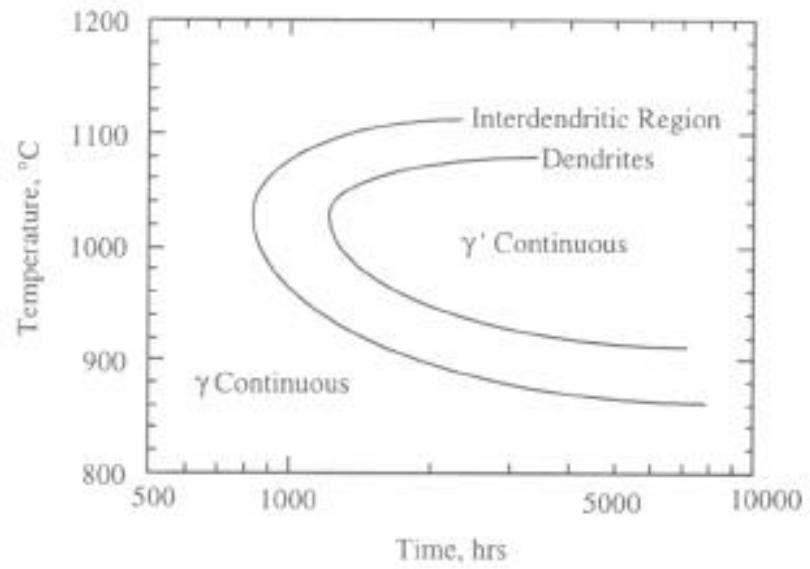

Figure 6. Schernatic of times and temperatures at which the $\gamma$ phase becomes continuous in creep rupture tests.

The high volume fraction of $\gamma^{\prime}$ precipitates remained cuboidal in all rupture tests below $850^{\circ} \mathrm{C}$, while precipitate rafting oceurred at higher temperatures. Interestingly, there was an inversion such that the $\gamma$ phase became the continuous phase in the temperature range of about 900 $1100^{\circ} \mathrm{C}$ in many of the creep rupture specimens. Figure 6 summarizes the conditions under which the $\gamma^{4}$ phase became the continuous phase, and Figure 7 shows an example of the $\gamma / \gamma$ inversion at $982^{\circ} \mathrm{C}$. Figure 6 also serves as a measure of the rafting kinetics of Rene N6. As long as the $\gamma$ phase temains cuboidal, the $\gamma$ phase continues to be the matrix phase. When rafting initiates, the $\gamma$ phase begins to become surrounded by the $\gamma$ phase. This inversion is a function of the dendritic structure because of the segregation present in the alloy. The interdendritic region contains a slightly higher volume fraction of $\gamma$, as well as a lower amount of refractory elements. Both of these factors cause the interdendritic region to initiate rafting and $\gamma \gamma \gamma$ inversion at earlier times.

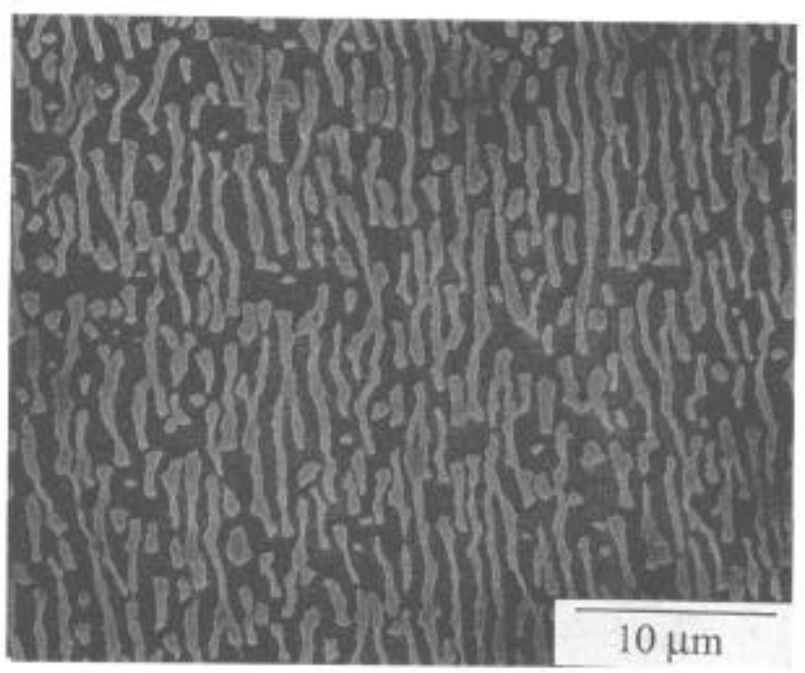

Figure 7. Example of the continuous $\gamma$ phase following a $982^{\circ} \mathrm{C}$ creep rupture test.

While the $\gamma^{\prime} \gamma$ inversion is not a common phenomenon in superalloys, it has been observed in other single crystal superalloys. [17.18] Examination of the creep and rupture properties showed no detrimental effect of the $\gamma \gamma$ inversion. Thus, the $\gamma \gamma$ interface appears to still be the key barrier to creep deformation. as previously observed in single crystal superalloys. ${ }^{[19,20]}$

A stable microstructure with respect to SRZ and cellular colonies was a primary goal for René N6 since a prior experimental single crystal superalloy. Alloy $5 \mathrm{~A}$, was subject to the development of SRZ under coatings and occasional cellular colonies in the microstructure, which severely reduced creep rupture properties. ${ }^{[4]}$ Developing screening tests for both the SRZ and cellular colonies required some knowledge of the mechanisms responsible for nucleation. Based on work on alloy $5 \mathrm{~A}$ and similar alloys, it was known that Re played a key role in the formation of these instabilities. Surface preparation also seemed to 
affect the nucleation of the SRZ beneath the coating. The cellular colonies in the dendrite cores appeared to be caused by the large amount of $\mathrm{Re}$ in this region due to segregation during casting. The nucleation mechanism of the cellular colonies in the dendrites is unknown at this time. It is possible that a small TCP phase in the dendrite core could serve as a nucleation site.

The screening test developed for SRZ beneath a coating involved applying a coating to a cube which had each face prepared with different surface finishing processes. The specimen was then exposed at 982 and $1093^{\circ} \mathrm{C}$ for 400 hours to promote SRZ formation. The linear percent SRZ formed under the coating around the periphery of the specimen became the parameter used to rank alloys. A value of $100 \%$ indicated that SRZ was continuous beneath the coating around the entire periphery of the specimen. The depth of the SRZ was not measured in this analysis. Screening for cellular colonies in the dendrite cores was performed on as-cast specimens to accentuate the segregation. Thus, if an alloy did not form cellular colonies in this case, it would likely be free from cellular colonies in solution heat treated material. A $1093^{\circ} \mathrm{C}$ exposure for 400 hours was utilized on the as-cast specimens.

Each candidate alloy was screened using the above tests for SRZ and cellular colonies. Statistical analysis of these results produced the following empirical expression for the relationship between alloy chemistry and the linear \% SRZ:

$$
\begin{aligned}
{[\mathrm{SRZ}(\%)]^{1 / 2}=} & 13.88(\% \mathrm{Re})+4.10(\% \mathrm{~W})-7.07(\% \mathrm{Cr}) \\
& -2.94(\% \mathrm{Mo})-0.33(\% \mathrm{Co})+12.13
\end{aligned}
$$

The elements in this equation are in atomic percent. It is clear that Re is the most potent element for determining an alloy's propensity to form SRZ. Minor variations in the Al content of the alloy did not influence the formation of SRZ beneath the coating, however significant $\mathrm{Al}$ enrichment occurs bencath the coating, and it is believed that this plays a large role in the formation of SRZ. Interestingly, $\mathrm{Cr}$ and Mo had negative coefficients. Reasons for the beneficial effects of $\mathrm{Cr}$ and $\mathrm{Mo}$ are not well understood, however it has been observed that alloys that form typical sigma and mu TCP beneath coatings do not form SRZ as readily. This is likely because the TCP phases contain high levels of refractory elements, such as $\mathrm{Re}, \mathrm{W}, \mathrm{Mo}$ and $\mathrm{Cr} .^{[1,2]}$ Precipitation of TCP phases in the diffusion zone of the coating, removes these elements from the matrix and reduces the chemical driving force for SRZ formation. Thus, $\mathrm{Cr}$ and Mo may assist in preferentially forming TCP phases in the diffusion zone instead of SRZ.

It became clear, however, that the amount of TCP in the microstructure away from the coating was not a good indicator of the amount of SRZ that may form under a coating, as shown in Figure 8. The SRZ measurement shown in this figure was made in the manner discussed above, while the TCP measurement was an empirical value of the amount of TCP in the microstructure based on a scale of 0-10. Thus, the stability of the alloy with respect to TCP formation did not correlate well with the alloy's tendency to form SRZ. This means that the driving forces for SRZ nucleation beneath a coating are different than the driving forces for TCP precipitation in the base alloy.

Equation 1 was used successfully to aid in developing alloys that had little or no SRZ under all types of environmental coatings. Control of the coating parameters was also found to be very important in reducing the amount of SRZ. By utilizing the correct coating process, René N6 does not readily form SRZ beneath aluminide, platinum aluminide or overlay coatings. Occasional SRZ has been observed under some conditions, but this has not been found to be detrimental. Using the screening tests described above, Figure 9 displays typical amounts of SRZ found beneath a PtAl coating on the third generation alloys, alloy 5A, CMSX10Ri and René N6. CMSX-10K was not evaluated in this study because analysis of the composition suggested that CMSX-10Ri was the more stable alloy. The balance of the refractory elements in Renc N6 resulted in the most favorable coating compatibility compared to similar alloys.

The most important criteria for the successful development of Rene N6 was to avoid the formation of cellular colonies in the dendrite cores. Using the as-cast specimen described above, each candidate alloy was evaluated for the propensity to form cellular colonies. All failed creep rupture specimens were also evaluated for the presence of cellular colonies. By lowering the Re content and controlling the level of the other refractory elements, René N6 was absent of cellular colonies using the screening test. An extended solution heat treatment was applied to René N6 to further ensure the absence of the cellular colonies. Alloy $5 \mathrm{~A}$ did show cellular colonies after the screening test, while CMSX-10 did not. It is believed that CMSX-10 did not precipitate cellular colonies in this test because of the relatively high amount of TCP phase precipitation that occurred in the as-cast and solution heat treated condition, as previously shown in Figure 5. A large amount of TCP precipitation reduces the driving force for cellular precipitation by removing the refractory elements from the supersaturated $\gamma$ matrix.

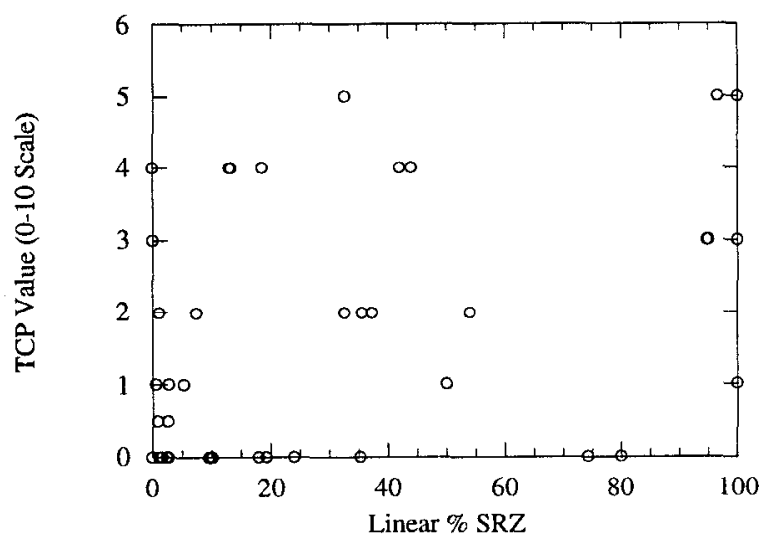

Figure 8. Measurements of SRZ beneath coatings and TCP in the microstructure showing no relationship between the two types of instability. 


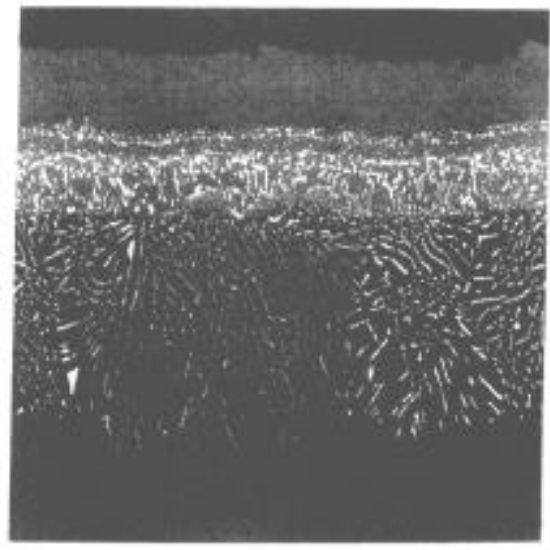

(a)

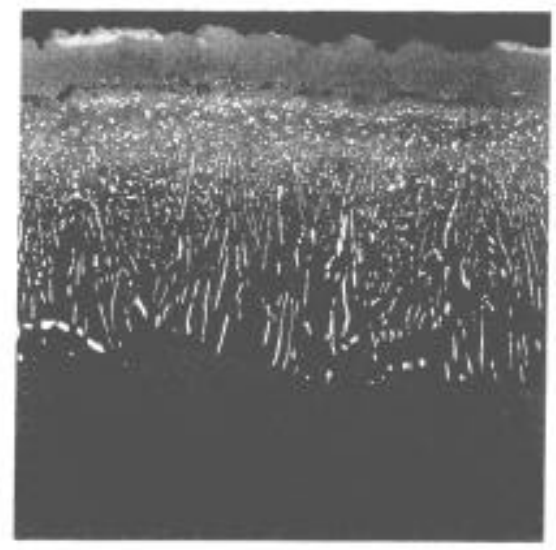

(b)

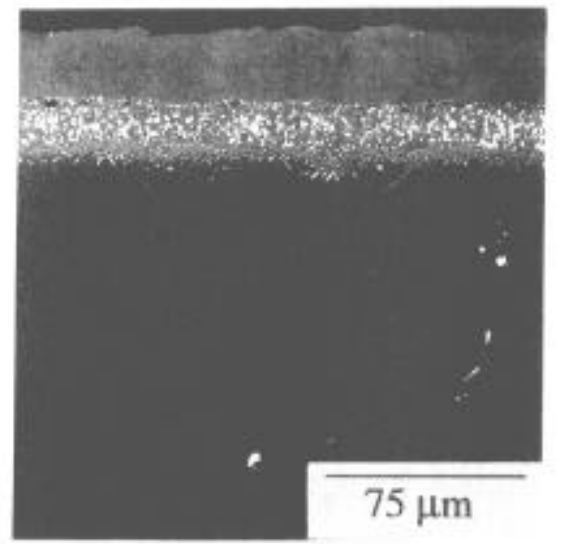

(c)

Figure 9. Typical amounts of SRZ observed beneath a PtAl coating afier a 400 hour exposure at $982^{\circ} \mathrm{C}$ in (a) alloy $5 \mathrm{~A}$, (b) CMSX-I0Ri and (c) René N6.

\section{Properties}

A comprehensive design data package containing a wide range of physical and mechanical properties has been generated. The physical properties of René N6 are very similar to other single crystal superalloys and will not be discussed further. Characterization of the mechanical properties of René N6 included over 450 creep rupture tests covering a wide variety of master heats, specimen configurations and coating variables. This included over 100 tests with rupture lives greater than 1000 hours and many over 5000 hours. The stress dependence of the minimum creep rates at several temperatures for Rene N6 are shown in Figure 10. Creep stress exponents ( $\mathrm{n}$ ) are in the range of 6.1 to 10.8 , simitar to other single crystal alloys. ${ }^{[21-23]}$ René N6 retains good creep strength even at temperatures as high as $1200^{\circ} \mathrm{C}$. Selected creep rupture properties at $982^{\circ} \mathrm{C}$ are shown in Figure 11 . In this figure, the specimen configuration was a $30 \mathrm{mil}$ sheet specimen with a platinum aluminide coating designed to better simulate the turbine airfoil compared to a larger, cylindrical specimen. René N6 displays about a $30^{\circ} \mathrm{C}$ benefit compared to René N5. The creep rupture properties are summarized in Figure 12 showing a Larson Miller Parameter comparison between René N5 and René N6. The $30^{\circ} \mathrm{C}$ advantage over René N5 is maintained even at the higher temperatures and longer times due to the good microstructural stability of René N6.

A wide variety of tensile, low cycle fatigue and high cycle fatigue tests have also been performed. The advantages shown in the creep rupture properties over Rene N5 generally held for the tensile and fatigue properties. For example, in LCF at $982^{\circ} \mathrm{C}$ and $\mathrm{A}=\infty$, René N6 had a 140 $\mathrm{MPa}$ advantage over René $\mathrm{N} 5$, and in $\mathrm{HCF}$ at $1093^{\circ} \mathrm{C}, \mathrm{A}=1$, René $\mathrm{N} 6$ had a $40 \mathrm{MPa}$ advantage over René N5.

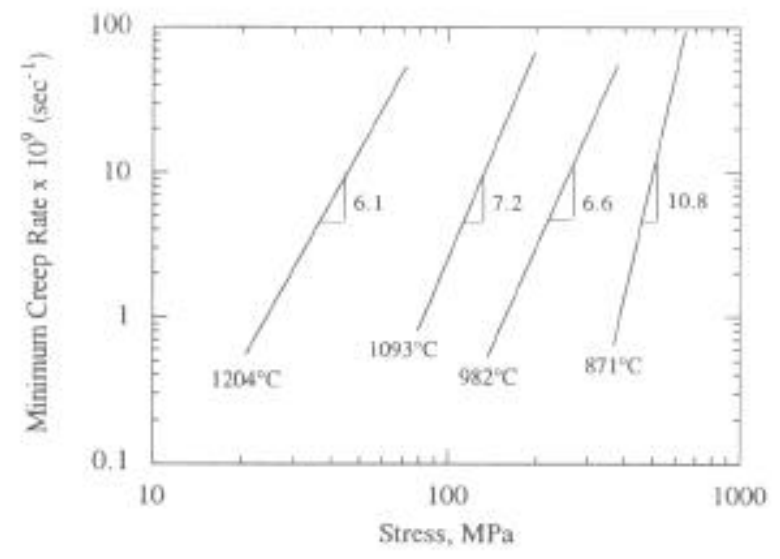

Figure 10. Stress dependence of the minimum creep rate for René N6 at several temperatures.

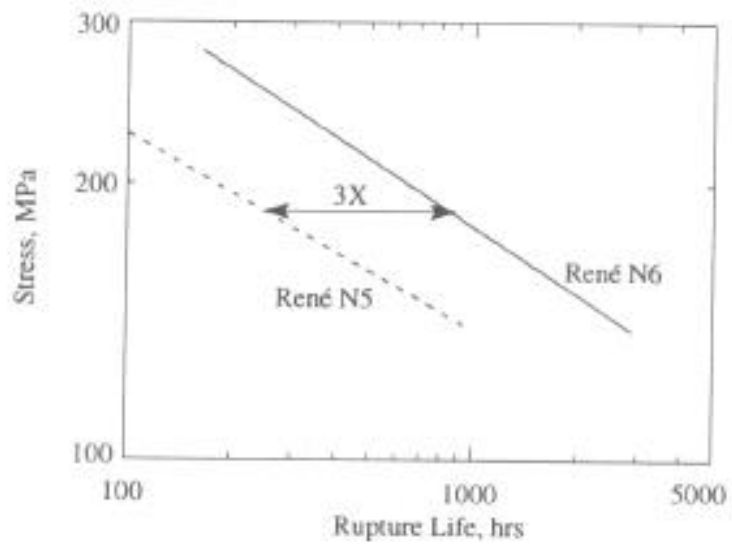

Figure 11. Creep rupture properties of thin wall, PtAl coated specimens tested at $982^{\circ} \mathrm{C}$ for René N5 and René N6. 


\section{Production Experience}

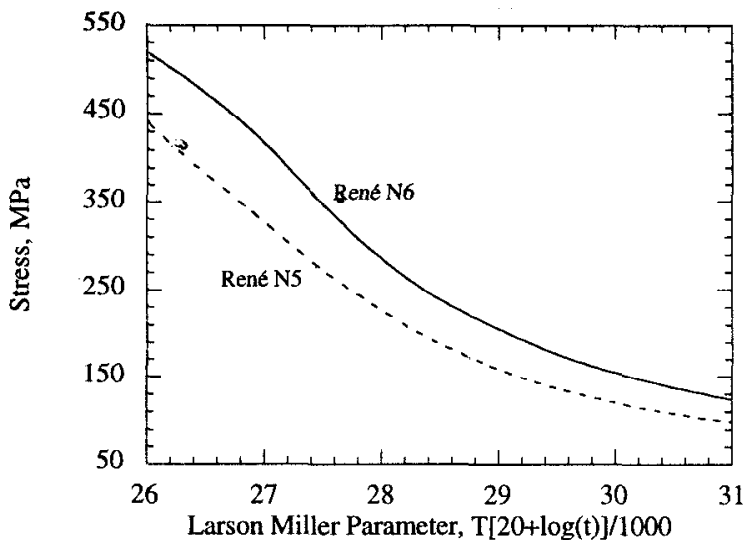

Figure 12. Comparison of the rupture strength of René N6 to René N5 using the Larson Miller Parameter.

The environmental resistance of René $\mathrm{N} 6$ is excellent relative to comparable single crystal and directionally solidified alloys. Despite the slightly lower $\mathrm{Cr}$ and $\mathrm{Al}$ content compared to previous alloys, René N6 develops a protective alumina scale that is enhanced by yttrium additions to the alloy. Unlike previous results on CMSX-4, ${ }_{r}^{[24]}$ there were no detrimental effects of ytrium on mechanical properties. Figure 13 shows the results of an $1177^{\circ} \mathrm{C}$ Mach 1 burner rig oxidation test performed on uncoated specimens. It can be seen that René N6 compares favorably to the excellent oxidation resistance of René N5 and is superior to other single crystal superalloys, such as PWA 1484 and CMSX-10Ri. The hot corrosion resistance of René N6 has been measured in several different tests with favorable results. The hot corrosion resistance of René N6 is similar to the high strength, directionally solidified alloy, René 142 , and slightly less than the excellent hot corrosion resistance of René N5. The application of environmental coatings further improves the oxidation and hot corrosion resistance. In addition, applying different techniques to reduce sulfur levels in René $\mathrm{N} 6$ has led to even better environmental resistance. ${ }^{[25,26]}$

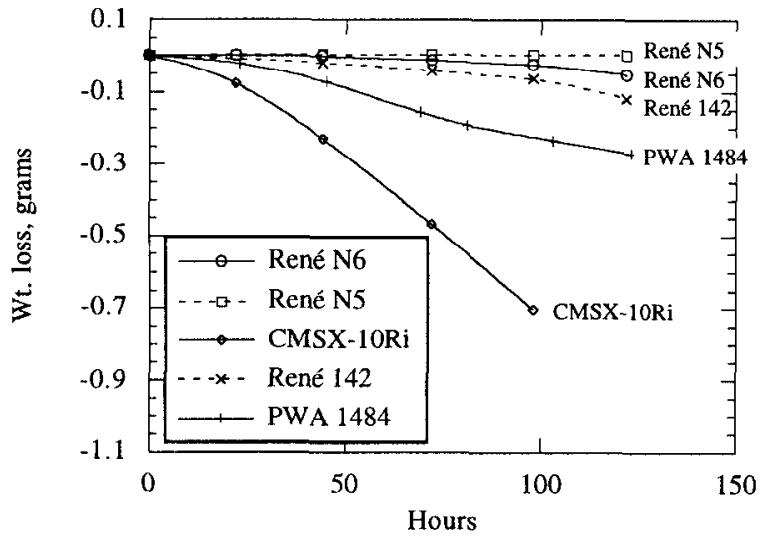

Figure 13. Comparison of several uncoated, single crystal superalloys in a $1177^{\circ} \mathrm{C}$, Mach 1 oxidation test.
René N6 has undergone extensive engine testing in a variety of turbine airfoil applications. Low pressure and high pressure turbine blades and vanes have been tested in sizes ranging from relatively small (F414) to large (GE90) airfoils. The castability of René N6 has been excellent in each of these applications and at least equal to prior alloys. The castability of René N6 was enhanced by designed experiments which identified compositional effects ${ }^{[5]}$ and processing changes to improve casting yield. The excellent manufacturability of René $\mathrm{N} 6$ has been demonstrated via a multitude of trials, such as brazing, hole drilling and machining.

The microstructural stability of the alloy allows the use of aluminide, platinum aluminide and overlay coatings. Thermal barrier coatings (TBC) have been successfully utilized on several turbine airfoil components. However, one of the advantages of René N6 is that the high strength of the alloy permits it to be used without TBC's with comparable performance to second generation single crystal superalloys with TBC. The high strength of René N6 has also been demonstrated through reduced creep and trailing edge bow of turbine airfoils following engine testing. For example, on one application of a large commercial engine turbine blade, there was no trailing edge bow on the René N6 blades, while René N5 blades had an average of 21 mils trailing edge bow. René N6 has completed extensive property and engine testing and currently is being used in production aircraft engines.

\section{Summary}

The development process for René N6 from the early stages of alloy development to production has been reviewed. The development of this alloy was faced with a unique challenge due to an instability phenomenon previously unknown to this class of alloys: SRZ. This is a cellular precipitation reaction that primarily occurs beneath coatings or along grain boundaries. A similar reaction also occurs in dendrite cores. Through better understanding of the mechanisms of formation of SRZ, alloy compositions were developed that avoided this instability. Thus, René N6 is compatible with all types of coatings and shows no property degradation from SRZ. In addition, René N6 does not form the very detrimental cellular colonies in the dendrite cores, which can significantly reduce crecp rupture propertics. Furthcrmore, good stability with respect to TCP phases was obtained, while improving the creep resistance of the material relative to second generation alloys. René N6 is approximately $30^{\circ} \mathrm{C}$ stronger than the second generation single crystal, René N5. Thus, René N6 represents the best combination of strength and stability in third generation single crystal superalloys. An extensive design data package has been generated, thorough engine testing with a variety of configurations has been completed and René N6 is currently being utilized for production engines. 


\section{Acknowledgments}

The authors gratefully acknowledge the contribution of Gary McCabe of GE Aircraft Engines who produced the slabs for the numerous heats involved in the development and scale-up of Rene N6. Other members of the alloy development team included Paul Fink, Ron Rajala, Stan Wlodek and Don Kirch. Particular thanks go to Dick McDaniel and Bob Allen who sustained funding for the development of René N6 and led the scale-up and introduction of the alloy into production hardware. The authors also acknowledge the efforts of Howmet and PCC in successfully conducting the many castability trials and scale-up efforts involved with René N6.

\section{References}

1. D. N. Duhl, "Alloy Phase Stability Requirements in Single Crystal Superalloys", Alloy Phase Stability and Design, ed. G. M. Stocks, D. P. Pope and A. F. Giamei, MRS, 1991, 389-399.

2. R. Darolia, D. F. Lahrman and R. D. Field, "Formation of Topologically Closed Packed Phases in Nickel Base Single Crystal Superalloys", Superalloys 1988, ed. D. N. Duhl, et al., TMS, 1988, 255-264.

3. C. M. Austin, R. Darolia, K. S. O'Hara and E. W. Ross, U.S. Patent $5,151,249$, "Nickel-Based Single Crystal Superalloy and Method of Making" - Alloy 5A, 1992.

4. W. S. Walston, J. C. Schaeffer and W. H. Murphy, "A New Type of Microstructural Instability in Superalloys - SRZ", Superalloys 1996, ed. R. D. Kissinger, et al., TMS, 1996,

5. T. M. Pollock, W. H. Murphy, E. H. Goldman, D. L. Uram and J. S. Tu, "Grain Defect Formation During Directional Solidification of Nickel Base Single Crystals", Superalloys 1992, ed. S. D. Antolovich, et al., TMS, 1992, 125-134.

6. E. W. Ross, C. S. Wukusick and W. T. King, U.S. Patent 5,399,313, "Nickel-Based Superalloys for Producing Single Crystal Articles Having Improved Tolerance to Low Angle Grain Boundaries", 1995.

7. E. W. Ross and K. S. O'Hara, "U.S. Patent 5,173,255, "Cast columnar grain hollow nickel base alloy articles and alloy and heat treatment for making" - René 142, 1992).

8. E. W. Ross and K. S. O'Hara, "Rene 142: A High Strength, Oxidation Resistant DS Turbine Airfoil Alloy", Superalloys 1992, ed. S. D. Antolovich, et al., TMS, 1992, 257-265.

9. C. S. Wukusick and L. Buchakjian, U.K. Patent Appl. GB2235697 "Improved Property Balanced Nickel-base Superalloys for Producing Single Crystal Articles" - René N5, 1991.

10. K. Harris and G. L. Erickson. U.S. Patent 4,643,782, "Single Crystal Alloy Technology" - CMSX-4, 1987.

11. D. N. Duhl and A. D. Cetel, U.S. Patent 4,719,080, "Advanced High Strength Single Crystal Superalloy Compositions" - PWA $1484,1988$.

12. X. Nguyen-Dinh, U.S. Patent 4,935,072, "Phase Stable Single Crystal Materials" - SC180, 1990.

13. G. L. Erickson, U.S. Patent 5,366,695, "Single Crystal NickelBased Superalloy" - CMSX-10, 1994.
14. W. S. Walston, E. W. Ross, K. S. O'Hara, T. M. Pollock and W. H. Murphy, U.S. Patent 5,455,120, "Nickel-Base Superalloy and Article with High Temperature Strength and Improved Stability" René N6, 1995.

15. W. S. Walston, E. W. Ross, K. S. O'Hara and T. M. Pollock, U.S. Patent 5,270,123, "Nickel-Base Superalloy and Article with High Temperature Strength and Improved Stability", 1993.

16. G. L. Erickson, "A New, Third Generation, Single Crystal, Casting Superalloy", JOM, April 1995(1995), 36-39.

17. R. A. MacKay and L. J. Ebert, "The Development of $\gamma / \gamma$ ' Lamellar Structures in a Nickel-Base Superalloy During Elevated Temperature Mechanical Testing", Metall. Trans, 16A(1985), 1969-1982.

18. A. Fredholm and J. L. Strudel, "On the Creep Resistance of Some Nickel Base Single Crystals", Superalloys 1984, ed. M. Gell, et al., TMS, 1984, 211-220.

19. M. V. Nathal, J. O. Diaz and R. V. Miner, "High Temperature Creep Behavior of Single Crystal Gamma Prime and Gamma Alloys", High Temperature Ordered Intermetallics III, ed. C. T. Liu, et al., MRS, 1989, 269-274.

20. T. M. Pollock and A. S. Argon, "Creep Resistance of CMSX-3 Nickel Base Superalloy Single Crystals", Acta Metall_mater. 40(1)(1992), 1-30.

21. W. Murphy, T. Pollock and R. Field, "Creep Mechanism Studies in René N5 and Related Single Crystal Superalloys", (GE Aircraft Engines internal report, 1991).

22. M. V. Nathal and L. J. Ebert, "The Influence of Cobalt, Tantalum and Tungsten on the Elevated Temperature Mechanical Properties of Single Crystal Nickel-Base Superalloys", Metall. Trans. 16A(1985), 1863-1870.

23. M. V. Nathal and L. J. Ebert, "Elevated Temperature CreepRupture Behavior of the Single Crystal Nickel-Base Superalloy NASAIR 100", Metall. Trans., 16A(1985), 427-439.

24. H. Mueller-Largent and D. J. Frasier, "Advanced Single Crystal Superalloy Processing Development for Ultra High Performance Fabricated Transpiration Cooled Turbine Airfoils", (Allison Gas Turbine Division, U.S. Navy Final Report NAPC-PE-225-C, 1991).

25. J. C. Schaeffer and W. H. Murphy, Unpublished Data, GE Aircraft Engines, 1992-1996.

26. M. A. Smith, T. H. Mickle, W. E. Frazier and J. Waldman, "Development of a Hydrogen-based Annealing Process for the Desulfurization of Single Crystalline, Nickel-based Superalloy", (Naval Air Warfare Center, U.S. Navy Final Report NAWCADWAR-95001-4.3, 1994). 